\title{
Un espacio donde escuchar al enemigo. Entrevista a Lola Arias
}

\author{
Débora G. Kantor \\ IDAES-UNSAM/CONICET, Argentina \\ debora.kantor@gmail.com
}

Fecha de recepción: 09/04/2021. Fecha de aceptación: 13/05/2021

\section{Resumen}

La entrevista recorre distintos temas transversales a la obra de la dramaturga, escritora y performer Lola Arias, desde Mi vida después (2009) hasta Futureland (2019), como el uso de los archivos públicos y personales, la tensión entre arte y política, la relación entre experiencia e historia, y su perspectiva acerca del espacio teatral, el trabajo con lo biográfico y la traducción.

Palabras clave: Teatro documental, archivo, arte, política, historia, espacio teatral, biografía, traducción

\section{The Stage as a Space to Listen to the Enemy. Interview with Lola Arias}

\begin{abstract}
The interview covers a variety of themes in the works of Lola Arias, from My life after (2009) to Futureland (2019), such as the use of public and personal archives in theatre, the tension between arts and politics and the relation between experience and history in her plays, as well as her perspective on the theatrical space and on the work with biography and translation.
\end{abstract}

Key words: Documentary Theatre, Archive, Arts, Politics, History, Theatrical Space, Biography,

Translation 
D.K.: Me gustaría empezar preguntándote por el trabajo con las imágenes en tu obra, buscar algún punto inicial para ingresar en ese tema. Para abrir con una cuestión muy puntual: pienso en el uso de los archivos de la cobertura de la Guerra de Las Malvinas en Campo minado (2016). Ahí, como en Teatro de guerra (2018), trabajaste con ejemplares de la Revista Gente que los combatientes no vieron hasta después de la guerra; de modo que se trabaja con el acontecimiento a través de unas imágenes y también una narración, es decir, una representación de la guerra que no solo no era diferente de la que tenían los combatientes, sino que, como se sabe, era también falsa. Esos ejemplares además son objetos que pertenecieron al padre de uno de ellos.

L.A.: El trabajo que a mí me interesa, que me interesó en el teatro, es el trabajo con los archivos personales. Y ese trabajo con el archivo personal, aunque hice otras obras documentales antes, empieza de una manera más fuerte en Mi vida después, donde la obra se construye a partir de este archivo que no son sólo imágenes, sino que a veces es también el sonido de los protagonistas. Y de, algún modo, es a partir del archivo, de las fotos de infancia, de las grabaciones en Súper 8, de las grabaciones en cinta, de los casetes de estos protagonistas, que empieza a reconstruirse no sólo la vida de ellos y sus padres, sino también la historia misma de la dictadura y de la generación que nació en esa época. Ese trabajo, que empieza en Mi vida después sobre esos archivos personales, sigo haciéndolo de maneras diferentes en otras obras y en la película también. En Campo minado, el archivo, digamos, es el archivo de la guerra, pero, a la vez, ahí hay una mezcla de archivos privados, personales, como las cartas que los soldados mandaban o recibían desde las Islas y también el archivo más oficial, que sería la representación de la guerra en los medios, y ahí voy a tu punto de la Revista Gente. A mí, lo que me interesa de la Revista Gente, como archivo de la guerra, como imágenes que circularon sobre la guerra, es que realmente esas imágenes construyeron el imaginario de mucha gente sobre lo que estaba sucediendo. De hecho, una de las tapas tiene una imagen de la guerra que ahora no recuerdo exactamente cuál es, tendría que fijarme, pero el texto es "Estamos ganando"; entonces, lo que me interesa es cómo hay una narrativa de la guerra que se construyó a partir de los medios, en este caso a partir de la Revista Gente, donde había un fervor nacionalista que fue también, de alguna manera, fomentado por esas representaciones. En la obra, esa revista vuelve aparecer y se pone de relieve, con treinta y cinco años de distancia. Obviamente, ese imaginario que se construyó de la guerra era completamente falso: porque no estábamos ganando, porque todo lo que aparecía ahí era simplemente una manera de estimular el nacionalismo, porque todo lo que aparecía ahí no estaba basado en los hechos reales de lo que estaba sucediendo. Pero, por otro lado, me interesa que es a la vez un archivo personal, porque son las revistas que guardó el padre del soldado que fue a la guerra y el padre las guarda, porque en realidad es la única manera, y eso es lo que él dice: "estas revistas las guardó mi padre, las compraba mi padre mientras yo estaba en la guerra y me buscaba siempre en las fotos". Entonces, de lo que habla es de que esas revistas, que para muchos eran simplemente la manera de imaginar lo que estaba sucediendo en un territorio al que no teníamos acceso en ese momento, porque tampoco había medios cubriendo en vivo lo que sucedía, era también para otras personas, para esta persona, para el padre de uno de los chicos que estaban en la guerra, la única posibilidad de tratar de acceder a su hijo, que no sabía ni en qué situación estaba. A su vez, ese archivo tiene otro sentido en la obra, porque es el archivo que el veterano argentino le muestra al veterano inglés y el veterano inglés sí está en esas imágenes; el argentino no está, pero el inglés sí, y está, de hecho, en la tapa. Entonces, por eso Marcelo dice, en la obra y también lo dice en la película: "buscándome a mí nunca me iba a imaginar que lo iba a encontrar a él, o sea que te iba a encontrar en realidad a vos". 


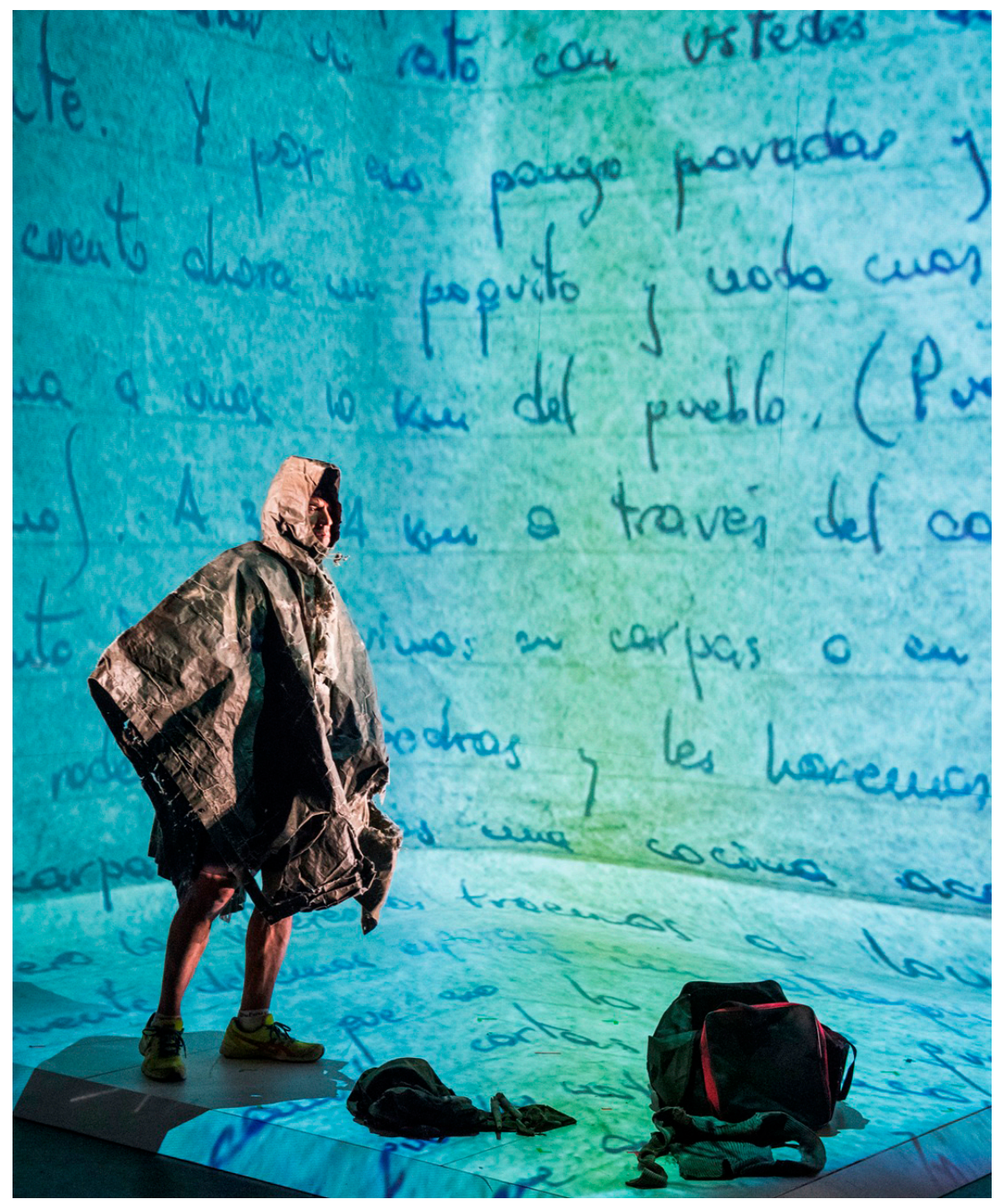

Campo minado - Foto: Tristam Kenton

D. K.:Tengo que ir y venir porque algunos temas se superponen, obviamente. En alguna entrevista leí una apreciación tuya, la entrevista era sobre la edición en libro de Mi vida después (2009), El año en que nací y Melancolía y manifestaciones, en la que decías que lo que para la generación anterior fue la militancia política, para la tuya fue el arte. ¿Cómo es la relación entre arte y política en tus obras? Esta etapa de Mi vida después, El año en que nací (2012) y Melancolía y manifestaciones (2012) tiene relación tal vez con una serie de películas como Los rubios de Albertina Carri o $M$., de Nicolás Prividera, que pusieron sobre la mesa algunas cuestiones generacionales similares a principios de los 2000.

L.A.: Esa frase habla de lo que fue para mí la operación en esas tres obras, que era una generación en espejo con otra: cómo mira una generación a la otra o cómo se ponen una frente a la otra. Yo creo que para los que nacimos en la época de la dictadura, entre el 76 y el 83, eso fue muy importante. Como que estábamos siempre en relación a esa imagen de nuestros padres: ¿qué hicieron en la dictadura?, cuando nosotros nacimos ¿qué hicieron?, ¿se exiliaron, colaboraron, fueron asesinados? Y eso marcaba quiénes 
éramos nosotros. Y por eso también esa idea de que ellos cuando fueron jóvenes creyeron en la política como la forma de cambiar el mundo, mientras que nosotros creímos que el arte podía cambiar el mundo. $\mathrm{O}$ creemos, no sé. Eso era lo que esa frase intentaba poner de relieve: el problema sobre aquello en lo que cree una generación. Y con respecto a las tres obras: una es de la generación nacida en la dictadura argentina, la otra, sobre la generación nacida en la dictadura chilena y la tercera es un poco más yendo a mi historia personal. Pero sí, hay ciertos procedimientos que se pueden encontrar en las tres obras. Si Mi vida después está dentro, sí, yo supongo que sí, está dentro de un momento histórico-cultural en el que aparecen una serie de representaciones de hijos que toman la palabra para hablar de lo que sucedió: de los años 70 desde su propia posición y creo que eso era algo que no existía, supongo, antes del 2000 tan fuertemente. La pregunta de los hijos sobre lo que sucedió, no la pregunta de los que vivieron la historia, sino la pregunta de los que llegaron después; es decir, de qué manera nuestra propia vida como generación estaba marcada por ese suceso. Hay varias novelas que también trabajan eso, de la época; está la novela El cuerpo en que nací de Guadalupe Nettel, que es en México, pero un poco trabaja esa historia, después está el libro de Patricio Pron, El espíritu de mis padres sigue subiendo en la lluvia, y después está Formas de volver a casa de Alejandro Zambra, que también escribe sobre su propia historia, la historia de sus padres y la dictadura. Creo que sí, que fue como un momento. O sea, hay una serie de representaciones en el cine, en la literatura, en las que los hijos están pensando a los padres. Algo que es una especie de necesidad histórica, la cuestión de cómo una generación piensa a la otra, una generación que alrededor de los 30 años decide pensar quién soy en relación a qué hicieron los que estuvieron antes.

D. K.: Claro, pero claramente ahí se da una relación entre representación y política o entre arte y política que, por supuesto, no hay motivo para pensar que se haya detenido, es una es una fuerza que perdura de alguna manera y que se puede buscar en la persistencia de algo temático o en alguna fantasmagoría en un procedimiento, por ejemplo. Entonces, ¿qué vino después?, ¿qué vino a partir de eso?

L.A.: En mi trabajo la relación entre arte y política siempre estuvo y siguió en Campo minado y también cuando hice What they want to hear (2018) en Alemania o Atlas del comunismo (2016). Es algo que me interesa, pero me interesa en relación a lo personal: en ese sentido es como el lema feminista de "lo personal es político". Digo: cómo reconstruir la historia a partir de las historias personales, cómo pensar problemas o circunstancias políticas desde adentro de la vida de las personas que lo vivieron, que tomaron decisiones, que pensaron que sus vidas podían transformarse, o que podían transformar la vida de los otros. Pero, siempre a una escala muy de lo humano y de la persona; por eso muchas de las obras que yo hago están basadas en la biografía y en cómo esa biografía se inserta en un determinado conflicto o en un determinado hecho histórico o momento político y cómo esas biografías nos hacen pensar más por afuera y ver la situación por afuera y por adentro, ¿no? Cómo esas biografías nos traen lentes para mirar algo que, como la historia del comunismo, puede ser muy abstracto: Atlas del comunismo era un libro que yo tenía cuando era chiquita, en el que había fotos de los grandes líderes comunistas, signos comunistas y un relato heroico del comunismo. Por contrapartida, justamente lo que intenté trabajar en la obra, fue el comunismo en la vida de ciertas personas -en este caso, de una serie de mujeres y trans-, que vivieron en la RDA. Esa es un poco la forma en la que esa tensión entre arte y política está siempre en mi trabajo.

D.K.: Bueno, ya que hablaste de Atlas del comunismo pasamos a eso. Hay un aspecto de la que tiene que ver con la traducción y con la cohabitación de un espacio. Me impresionó mucho cuando la vi, por ejemplo, la coexistencia de esta espía 
de la RDA con la cantante, que se encuentran de pronto en un escenario que no hubiera sido posible, o sea se hubieran encontrado de una manera completamente distinta antes y se encuentran de este modo ahora. Hay algo de ese hecho que es profundamente político y a la vez es muy difícil de atrapar. Es un poco desbordante. Quería preguntarte sobre eso, sobre qué procedimiento hubo ahí.

L.A.: Sí, hay algo de mi trabajo que de alguna manera produce una serie de experimentos sociales: juntar a todos los hijos de la dictadura significa juntar a un montón de personas, en el caso de la obra chilena era muy evidente, cuyos padres estuvieron en lados opuestos; unos eran hijos de militares o de policías y otros eran hijos de militantes que tuvieron que exiliarse o que desaparecieron o que fueron asesinados. Había una idea de producir ese experimento social en el que estas personas, que tienen esos pasados y esas historias familiares que los enfrentan, se encuentran y reconstruyen la historia de un país. Esa operación, esa idea del experimento social, que yo hice en Mi vida después y en El año que nací, se va como acentuando en Atlas del comunismo y también en Campo minado, al punto que, en Atlas del comunismo ya no son las historias acerca de los padres, sino que son ellas mismas las que estuvieron de los dos lados. La espía que denunciaba a los disidentes y la disidente punk que escribía letras en contra del gobierno de la RDA y que estuvo en la cárcel, se encuentran. "Se encuentran" quiere decir que el espacio del teatro es un lugar también -y eso me interesa-, el teatro es un lugar que permite eso del experimento social y que ese experimento social se convierta en arte: no es simplemente arrojar a dos personas en una sala, sino que es cómo esa operación artística permite que esas dos personas puedan encontrarse y pensar acerca de qué hicieron y dónde estaban y cómo fue su vida adentro de la RDA. Esa convivencia que permite el teatro, ese lugar neutral que es el teatro, casi como si fuera un territorio neutral, para que permita ese encuentro, es algo que después así como lo trabajé en Atlas del comunismo, lo volví a trabajar en Campo minado de una manera más evidente, porque en ese caso eran antiguos enemigos, personas que combatieron unas contra otras, que podrían haberse encontrado en el campo de batalla, ahora se encuentran en teatro para reconstruir su historia o sea que, de alguna manera, es algo que fue evolucionando en las obras: cómo es el trabajo -que es un trabajo también político- de escuchar al enemigo, de entender, de poder crear ese espacio donde puedo escuchar al enemigo, donde puedo entender la posición del otro.

D. K.: A propósito de eso, pensaba que, tanto en Campo minado como en Teatro de guerra, hay una tensión que está como suspendida, no está ausente, pero ésta, se manifiesta a veces, cuando discuten acerca de la soberanía de las islas, por ejemplo, pero después se dispersa, va, digamos, mutando en las acciones, en los gestos. Me parece un aspecto para pensar puntualmente, ya que, por supuesto, esas personas eran beligerantes, en todo sentido. ¿Cómo trabajaste esa tensión?

L.A.: Bueno creo que lo que vos describís como tensión es justamente lo que más me interesa, me interesa que adentro de una obra haya esa especie de tensión, esa especie de incomodidad, esa especie de algo que no está resuelto porque tanto en El año en que nací, como en Atlas del comunismo, como en Campo minado, en todas hay una cuestión irresuelta, porque no es que el hecho de que estén juntos en el escenario significa que estén de acuerdo, ni que se hayan perdonado: significa que están conviviendo, que es como convivir en el disenso, digamos, tiene que ver con cómo convivimos en el disenso: no necesitamos estar de acuerdo, podemos escucharnos y pensar, y para mí eso es lo más político de esas obras, que no buscan resolver sino dejar la tensión arriba del escenario, para que también el público tenga esa sensación de tensión, de irresuelto, porque es un conflicto irresuelto. Por más que ellos, los excombatientes, puedan ahora convivir, ser amigos, incluso desarrollar una relación muy cercana unos 
con otros, eso está atravesado por la tensión de que el conflicto sigue abierto, de que Argentina sigue reclamando la soberanía de las Islas y de que los ingleses dicen "las Malvinas son inglesas" y los argentinos dicen "las Malvinas son argentinas". Entonces me parece que justamente el trabajo del arte no es resolver el problema sino ponerlo sobre la mesa, hacerlo visible.

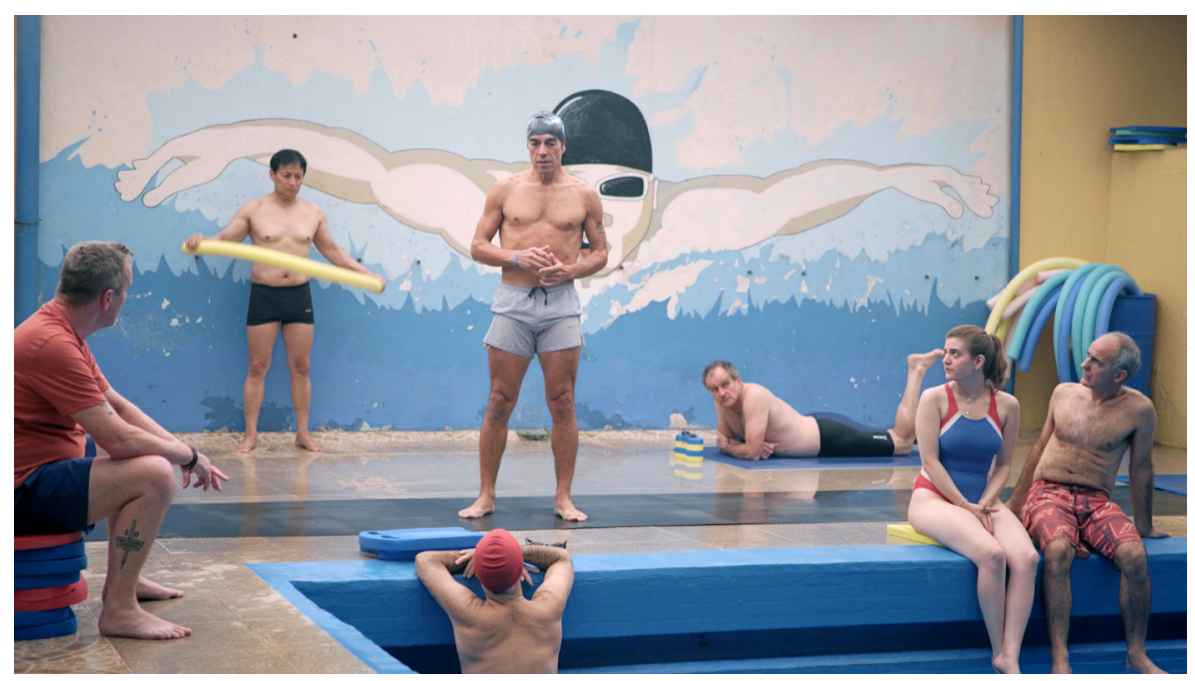

Teatro de guerra. Fotograma: Manuel Abramovich

D. K.: Leí en muchas entrevistas que te preguntaban acerca de la, digamos, cuestión terapéutica en estas obras; es una pregunta muy frecuente que te hacen. Quería volver un poco sobre eso para pensar, en realidad, la cuestión de la de la ética. Quiero decir, acerca de "quién decide" lo que se trae al escenario. Porque, obviamente, trabajar a partir de un elemento biográfico tiene un costo.

L.A.: La cuestión del aspecto terapéutico para mí es siempre interesante. Yo soy una persona que hace psicoanálisis desde los tres años, empecé realmente como niña jugando con juguetes en el consultorio psicoanalítico, haciendo mis mini-obras sobre la mesa del consultorio. Con lo cual, la idea de pensar sobre la propia vida es algo que siempre me interesó, no es un aspecto que me parezca menor. Pero también sé que yo no soy psicoanalista, soy artista: me interesa eso, pero no pretendo, en ese sentido, que el arte cure. Sí creo que el arte ayuda a entender, a visualizar, a pensar la propia vida, a tomar una posición diferente con respecto a la propia historia, a organizar una nueva narrativa y que, a veces, poder contar la historia de otra manera significa ya estar en otro lugar y ese estar en otro lugar puede ser que te ayude para seguir tu vida de un modo diferente. Entonces, sí, en ese punto creo que el arte hace cosas, hace cosas muy concretas en la vida de las personas. En su psicología, en su forma de pensarse a sí mismas, en las decisiones que van a tomar después de haber hecho una obra, como cuando hicieron cada una de las obras, pero también sé que hay partes en las cuales o hay lugares en los cuales yo no puedo dar el apoyo que quizás las personas necesitan cuando se abren puertas que estaban cerradas desde hace mucho tiempo y salen cosas que ni siquiera yo sabía que estaban ahí. Y por eso lo que yo hago es siempre trabajar con equipos muy grandes de gente y tener dentro del equipo a psicólogos o terapeutas o un grupo de terapeutas. O sea, tener un apoyo profesional. En el caso, por ejemplo, de Campo minado, yo tenía el apoyo de un centro de apoyo psicológico del veterano de guerra, que es un grupo de psicoanalistas, psicólogos expertos en trauma que nos prestaron ayuda en ciertos momentos del trabajo. En la última obra que hice acá en Alemania el año pasado, que se llama Futureland (2019), un grupo de menores no acompañados, 
chicos que llegaron solos a Alemania cuando tenían entre 10 y 15 años desde Afganistán, Siria, Somalia, de diferentes lugares del mundo, escapándose de situaciones de guerra y de pobreza extrema, reconstruyen de alguna manera su proceso de integración a la sociedad alemana. Ahí también, por ejemplo, trabajé con una institución que se especializa en el trauma de los menores migrantes. Siempre trato de tener algo, alguien, una institución detrás que pueda dar un apoyo más del que yo puedo dar desde adentro del mundo artístico. Pero por supuesto que todo el tiempo hay montón de decisiones que se toman en el proceso de hacer una obra documental que tienen que ver con consensos, digamos. Del tipo "bueno, esto no lo vamos a poner en la obra porque es demasiado para esta persona" y esta persona dice "yo a esto lo cuento, lo puedo hablar, pero no quiero trabajar sobre esto". Hay un montón de momentos en los que los espectadores o las personas que tienen acceso a esos materiales creen que está todo. Pero no está todo, hay mucho más de hecho, que no está, que fue compartido y quedará en el mundo del ensayo, de lo que se habló, pero no está todo porque hay muchas veces en que uno toma una decisión para preservar a una persona de algo que sería demasiado, y hay veces en las que la persona misma dice "yo quiero esto, quiero contar esto, aunque es doloroso y terrible, quiero contarlo", y ese mismo acto de contar y de contarlo 158.000 veces, lo pone en otra posición. Eso hace un trabajo en esa persona que, si no hubiera hecho 150 veces la obra, y dicho 150 veces cómo vio morir a... quizás estaría mucho peor, digamos, en un sentido psicológico de lo que está habiéndolo contado 150 veces. Eso, en ese sentido, es un aspecto bastante misterioso y bastante sorprendente de cómo opera el acto mismo de contar.

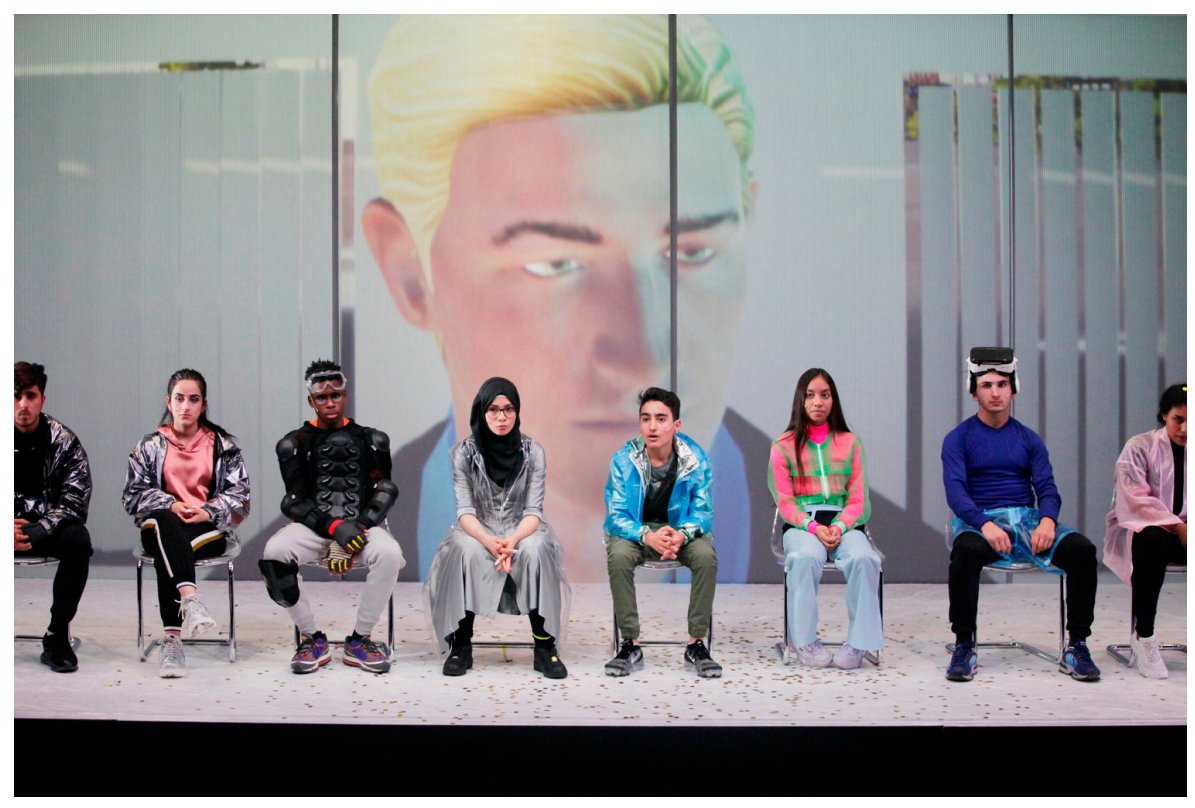

Futureland. Foto: Ute Langkafel

D. K.: Hay un trabajo también sobre el propio cuerpo que es muy impresionante. En esa repetición se puede ver un trabajo sobre la corporalidad de la memoria, como si se tradujera en un control del cuerpo ese control también del relato.

L.A.: Sí, bueno, la idea del reenactment, el volver a representar o a reconstruir una historia del pasado con el cuerpo, significa también volverla a pasar por el cuerpo. O sea que no es solo el relato de alguien que se sienta y cuenta la anécdota, sino que al poner el cuerpo se pone, digamos, en funcionamiento toda otra serie de mecanismos y afectos y cosas, que vienen con el poner el cuerpo. Por eso es teatro y no son entrevistas, simplemente. 
D. K.: Por último, me interesa mucho preguntarte por el tema de la traducción. Me voy a referir a Teatro de guerra, pero claro que es algo para pensar en toda tu obra. Quería retomar una secuencia en la que Sukrim, el veterano nepalés, habla en una videollamada acerca de que él no habla inglés y no habla español, de que queda como perdido entre esas dos lenguas. Creo que es interesante tomar ese momento para pensar cómo el acto de traducción se va desdoblando en la película y en la obra (Campo minado).

L.A: Bueno, en Campo minado la traducción fue un tema fundamental, porque ni los ingleses hablaban español, ni los argentinos hablaban inglés, con lo cual el equipo artístico se convirtió como en un puente, los traductores o las traductoras de un lado al otro. Y yo creo que eso hizo que a la vez el encuentro entre ellos estuviera mediado por el arte, porque eran las los artistas los que traducían de un lado a otro lo que lo que estaba pasando. Y para mí fue muy importante, específicamente en Campo minado, que las dos lenguas tuvieran la misma entidad, que la obra fuera mitad en inglés y mitad en español y que el público tuviera que leer subtítulos. Digamos, si estamos en Argentina tenías que leer los subtítulos al español de los ingleses que hablan inglés y que si estábamos en Inglaterra tenías que leer los subtítulos al inglés de los argentinos que hablaban en español. Esto ponía de manifiesto la entidad de las dos lenguas como parte del conflicto y como parte de la disputa. El problema de la traducción en relación a Sukrim es que él es nepalés y que, aunque haya sido incorporado al ejército inglés, su lengua materna es el nepalés, traía otra serie de conflictos, que es, cómo se incorporaba esa tercera cultura adentro de la obra y, de hecho, en la película se ve ese momento en que él habla con la mujer, que es una conversación por videollamada real, donde básicamente él cuenta el conflicto de ser una minoría total y estar perdido entre las dos lenguas. Nosotros intentamos tener un traductor de nepalés, pero lo que conseguimos en Argentina era un chico que era cocinero en un restaurante, que nos traducía más o menos las cosas que decía Sukrim, porque ni siquiera hablaba el dialecto de Sukrim exacto, con lo cual había muchas cosas que se perdían en la traducción. Yo creo que, de alguna manera la obra trata de hacer visible ese problema de la traducción, poniendo también todos esos elementos a la vista, no escondiendo, no tratando de que todos hagan como que se entienden o que todos hablen el mismo idioma. 